\title{
What are Fundamental Motor Skills and What is Fundamental About Them?
}

\author{
Karl M. Newell \\ University of Georgia
}

\begin{abstract}
A review and synthesis of the literature on the learning and development of motor skills supports the postulation that whether a motor skill can be deemed fundamental is dependent on the collective presence of three conditions: (i) uniqueness to the movement pattern and/or outcome; (ii) near universality of the functional outcome in the healthy population; (iii) capacity to act as an antecedent influence supporting generalization to a large and broad set of perceptual-motor skills. Within this framework, it is proposed that the infant motor development sequence underpinning upright posture (e.g., sitting, bipedal standing), locomotion (e.g., walking, running), and object-interaction (e.g., grasping) represents the minimum set of fundamental motor skills from which all other skills evolve with over the lifespan. This position is in contrast to the views of many students of motor development and learning who describe numerous skills that typically emerge in the $\sim 2$ - to 18 -year-old range as fundamental but do not meet the criteria outlined here to be fundamental. It is proposed that these be labeled as core developmental activities having a more restricted but still practically relevant influence on the acquisition of and generalization to other motor skills.
\end{abstract}

Keywords: instruction, intervention, motor assessment, motor development, movement patterns, movement skills, ontogeny, phylogeny

There have been many efforts to provide a classification or taxonomy of human perceptual-motor skills ${ }^{1}$ (e.g., Burton \& Rodgerson, 2001; Fleishman, Quaintance, \& Broedling, 1984; Gentile, 1987; Poulton, 1957; Schmidt \& Lee, 2012; Seefeldt, 1980; Singer \& Gerson, 1981; Warren, 2006; see Magill \& Anderson, 2014). These classifications are primarily descriptive and unidimensional to a single perceptual-motor property of the task constraints and related to a respective theoretical emphasis of the time period. Furthermore, and of relevance to this paper, is that of the preceding list only Burton and Rodgerson (2001) and Seefeldt (1980) directly address the issue of fundamental motor skills in a developmental context. This is in spite of the fact that motor development texts over the years have shown that the emerging and

Newell (Kmn1@uga.edu) is with the Department of Kinesiology, University of Georgia, Athens, GA, USA. 
growing repertoire of motor skills in the developing child naturally lends itself to classification and taxonomy (Haywood \& Getchell, 2020; Sugden \& Wade, 2013).

Taxonomy is that branch of science that seeks classification and naming of phenomena based upon shared characteristics. Taxonomies are particularly prevalent in the many disciplines of biology and the life sciences and can have different purposes. In the present context, a taxonomy of perceptual-motor skills should specify the dimensions of description that underpin the organization of the tasks into categories, most importantly the principles on which each set of tasks develops and generalizes to others in the same set. By implication, a task classification of this type should facilitate the development of principles for designing assessment instruments and intervention strategies in teaching, coaching, and therapy for movement skills.

Among the many extant attempts to classify motor skills, a concept that frequently occurs is the concept of "fundamental". Unfortunately, a vast range of skills are assigned the label fundamental and there is actually rather little discussion of what the term means. For example, at one end of the spectrum we have Wickstrom's (1977, p. 3) simple and straightforward definition that a fundamental skill is a common motor activity with a general goal. This definition would seem unlikely given the recent active level of publications and conference talks in regard to nomenclature and classification of fundamental motor skills (e.g., Barnett et al., 2016; Hulteen, Morgan, Barnett, Stodden, \& Lubans, 2018; Logan, Ross, Chee, Stodden, \& Robinson, 2018; Lubans, Morgan, Cliff, Barnett, \& Oakley, 2010). At the other end, we have the now widely held view that fundamental motor skills are those that provide the building blocks for learning the more complex actions of sport and physical activity in diverse contexts (e.g., Seefeldt, 1980; Sport New Zealand, 2012). But, what are these critical skills, on what basis have they been grouped together, and what is the evidence for their being the foundation stones on which the vast array of motor skills we learn over the lifespan are based?

The purpose of this article is to review the existing literature on the topic of fundamental motor skills to provide a coherent alternative account of what fundamental means and implies in the motor skills context. To this end, we begin by discussing the extant definitions of fundamental motor skills and the ways in which the term and related constructs have been used in the motor learning and development domain. The review reveals support for the proposition that there has been an over-estimation of the number and types of motor skills that are fundamental, particularly in the physical education and sport contexts.

The proposed outcome from the analysis and synthesis of the literature on motor skills is that three major classification criteria must all be met for a motor skill to be interpreted as fundamental. These criteria lead to the determination that the small group of task categories in infants-namely, locomotion, posture, and object-interaction ${ }^{2}$-are the fundamental motor skills at the task level of description. The progressive emergence of additional motor skills through childhood are interpreted as core developmental activities that have a more restricted though still practically relevant role to the acquisition of and generalization to other motor skills over the lifespan. 


\section{Classifying Fundamental Motor Skills and the Challenges of Nomenclature}

\section{Motor Skill Classifications}

Table 1A shows a broad array of extant motor skill categories and contexts in which motor skills occur that appear not to include the class of fundamental motor skills. The vertical order has fundamental motor skills as the base with more culturally promoted motor skills in succeeding rows of contextual expression. The list is not to be viewed as exhaustive but rather representative of the behavioral scope of the major motor skill classifications, although it could be amplified with more detail in the form of finer grain categorizations. For example, consider all the sub-classifications that could be listed as representative of a general sports category.

Furthermore, it is clear that many of the categories are not mutually exclusive, leading a perceptual-motor skill to potentially be in more than one of these skill classifications. Figure 1B shows some primarily descriptive motor control dimensions on which motor skills in Figure 1A could be contrasted. Thus, the classification of motor skills can take place on more than one dimension.

It is against the backdrop of the skill categories of Table 1A that the place of fundamental skills of motor development needs to be assessed. Indeed, it is instructive to take a brief consideration of the question as to which, if any, of the skill categories of Table $1 \mathrm{~A}$ are fundamental or could reflect fundamental motor skills? It appears that the traditions of a number of theoretical and practical emphases in and around motor development have created a small but diverse set of classifications of fundamental motor skills the contents of which are also within certain other motor skill categories of Table 1A, but not necessarily in an explicit way.

\section{Table 1 Categorization of Human Motor Skills and Category Characteristics of Motor Tasks}

A. Categorization of human motor skills embedded by function and context

Dance, Exercise, Musical Performance, Play, Sport, Work

Activities of Daily Living, Self-Help Motor Skills

Novel Body Configurations and Movement Forms

Posture, Locomotion, Manipulation, Communication

B. Some contrasting category characteristics of motor tasks

Fine and Gross Motor Skills

Closed and Open Motor Skills (Poulton, 1957)

Discrete, Serial, Continuous

Two Dimensional: Environmental Context/Function (Gentile, 1987)

Ballistic/Closed-Loop Control

Stability Characteristics (Warren, 2006) 


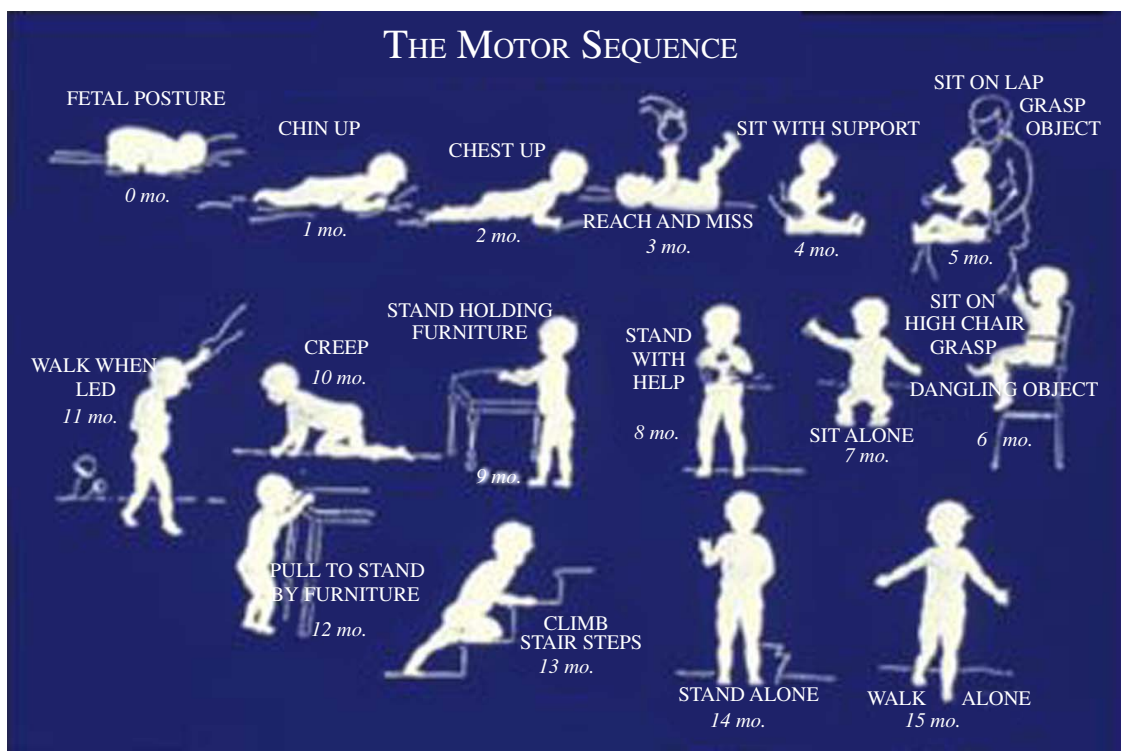

Figure 1 - The infant motor development sequence reproduced from Shirley (1931).

The interpretation of what constitutes a fundamental motor skill has been influenced by whether the classification is in the perspective of a basic multidisciplinary science of motor development over the life span or applied contextual perspectives with the more practical/clinical needs of the education, fitness, sport, and disability domains. Indeed, there are many frameworks of fundamental motor skills that have been proposed by individual scholars and orientations to motor development including educators in school and higher education systems. Moreover, government education and health agencies from several countries have formally identified and promoted the role of fundamental motor skills in the teaching and learning of the presumed more complex activities of physical education and sport through which the engagement in holds the potential of positive effects on the development of a healthy lifestyle (Colvin, Markos, \& Walker, 2016; Department of Health and Physical Education, 2011; Sport New Zealand, 2012; Department of Education, 1996).

Communication skills are included here in the taxonomy of motor skills in contrast to many accounts of motor development (see Table 1A). These movement skills are typically outside of consideration to fundamental motor skills, presumably due to the contextual emphasis from the practical orientation on the gross motor skills of physical education and sport. Nevertheless, from a general motor development perspective, independent of the politics of administrative units in academe and health agencies, the communication skills of speech, gesture, and writing seem to be to varying degrees candidates as motor skills if not fundamental motor skills. Indeed, speech can be viewed as a very elaborate and fundamental motor skill with theoretical positions in concert with those of motor development (e.g., Iverson, 2010; Luzzini-Seigel, Hogan, Rong, \& Green, 2015). American sign 
language is another important communication skill, though probably not fundamental as viewed in the framework developed here. In parallel, there is an underrepresentation of activities of daily living and self-help motor skills in the analysis and generalization of fundamental motor skills in development. Having made this case, our emphasis here is fundamental motor skills in the whole-body movement domains of activities of daily living, dance, exercise, play, and sport.

\section{Nomenclature-A Basic Problem}

The motor skills area is replete with poorly defined terms that we will unpack as needed to discern what is fundamental about the large array of motor skills that are given this label. There are also several different frameworks and orientations in theory and practice that have advocated or endorsed the idea of fundamental motor skills. It is axiomatic that the diversity of related but different labels for fundamental motor skills has contributed to the diversity of their interpretation (see Logan et al., 2018 for related concerns on definition and with data on use of the term in publications).

In addition to the differing definitions of the term fundamental, a complicating but perhaps background issue throughout this literature is the variation in the terms attached to the word fundamental (e.g., fundamental motor skills, fundamental movement patterns, and fundamental movements). A background issue throughout is the working definition of the different but related terms prevalent, including fundamental motor skills, fundamental movement patterns, and fundamental movements. Are these terms simply synonymous or are there meaningful shades of scholarly grey in the different labels? This question is examined as a precursor to reviewing the major classifications of fundamental motor skills (see Barnett et al., 2016; Logan et al., 2018; Magill \& Anderson, 2014; Wickstrom, 1977, for other accounts of the classification problem for motor skills).

It might be useful to have a working definition of the key term fundamental as used in the phrase fundamental movement skills. This is especially important at this juncture as there seems to have been several interpretations of the word fundamental and this has contributed to the broadening and ambiguity of the label fundamental motor skills. To help move forward on this issue let us consider two representative definitions of fundamental listed on Wikipedia and drawn from standard dictionaries.

Fundamental-definition in theCambridge English Dictionary (bolding by $\mathrm{KMN})$ :

- Fundamental meaning: 1. forming the base, from which everything else develops: 2. more important than anything else: 3 . being the most basic or most important

Fundamental-definition inMerriam-Webster Dictionary (bolding by KMN):

- Fundamental meaning: serving as a basis supporting existence or determining essential structure or function

The phrases 'being the most basic or most important' and 'a basis supporting existence or determining essential structure or function' are the significant 
operative elements of these definitions that need interpretation and instantiation if we are to have a common understanding of the label fundamental movement skills. Thus, it is not sufficient for a motor skill to be a precursor of another motor skill for it to be labeled fundamental. A fundamental motor skill needs to be defined at the most basic task level.

As will be subsequently shown, the descriptive applied classification approach to the development of motor skills tends to include many movement properties that on the surface are marginal in appropriateness or at first impression outside the bounds of fundamental motor skills. Thus, there are accounts of fundamental motor skills that include task constraints that arguably are not basic, essential, or important in the movement domain, although they may be distinct and can be useful in the learning and performance of particular physical activity and sport contexts. This observation is a reminder that the category of fundamental motor skills will be limited by definition to a set of core basic, essential important motor skills such that one might speculate that the number of these is an order of magnitude less than the number of activities or subskills in the physical activity domain that are not seen as fundamental. The challenge is establishing a framework to validly and reliably identify and generalize what is basic or essential (fundamental) in a motor skill.

The fundamental 'for what' question is also diversely interpreted in motor development along the lines of basic and applied research agendas. At the basic end of the research continuum the term fundamental is referring to the essential classes of motor skills based on a generic functional action classification from an evolutionary and developmental point of view. At the applied end of the continuum, the 'for what' of fundamental motor skills is the particular motor skill of local interest to the performer or instructor that brings specific task constraints in action to be realized. This is a more narrow and practical interpretation of the fundamental 'for what' question than that driven by an anthropological origin's perspective on the emergence of human motor skills (Sands \& Sands, 2010).

\section{Motor Skills, Movement Patterns, and Movements}

The term fundamental motor skill appears to be the most commonly used label for the issues at hand in this paper though other labels, particularly fundamental movement patterns and fundamental movements, are invoked in a parallel way. The position taken here is that there are meaningful differences in these labels (even if created unwittingly by authors) in that the terms are taken to emphasize different aspects of motor skills in action (see also Magill \& Anderson, 2014, chapter 1 for an overview). This in turn supports the observation that there are different dimensions of description to the prevailing taxonomies of fundamental motor skills. Motor skill is used here primarily in the sense of the functional task demands for a particular action (Newell, 1986) rather than also used as an adjective that captures the predictability and efficiency of the movement execution in the action.

Motor Skills. The term motor skills reflects a category of action that has an intentional and functional outcome or goal to be realized (Newell, 1978). The goal could be a particular movement pattern itself such as sitting and jumping, or as in the closed motor skills of gymnastics, high board diving, and ice skating. The goal could also be an outcome that is on a different dimension than the movement pattern as in a product of the movement such as distance thrown in javelin or time 
to swim $100 \mathrm{~m}$. In certain motor tasks the movement pattern and its functional outcome may both be emphasized explicitly or implicitly.

The relation of movement pattern and movement outcome continues to be a challenge in motor learning and control in part because the multiple degrees of freedom of the system provide for redundancy (Bernstein, 1967) and, moreover, the relation is task specific and degenerate (Edelman \& Gally, 2001). That is, typically there is more than one solution to movement coordination and control that can produce the same task outcome. It is assumed, however, that there are certain coordination, control, and skill solutions that are more efficient than others, even if the outcome of the action is essentially the same. Skill as an adjective is taken widely though implicitly as the learned ability to bring about a predetermined outcome, with maximal certainty, and the minimum outlay of time and energy, or both (Guthrie, 1935; Knapp, 1963).

The domain of motor learning and development has emphasized movement patterns and movement outcomes but it is commonly held that it is the perceived needs and functions that drive the movement properties of most actions observed in child development. The movement domain tends to say little about the role of needs and functions of the individual in motor learning and development. The above view represents a standard but narrow movement approach to the action problem in that it minimizes or even ignores the nature of the cause for the goals of the task (other than that is the need of the experimenter!). Note that passive movement does not fulfill the criteria for an action given that there is no intention to realize a particular goal.

Indeed, movement in action is typically a means to an end with an outcome that is on a different but related dimension of consideration. For example, people can and do walk to the supermarket to buy food. And, when standing and maintaining upright posture we are typically doing this in the service of another action goal, including looking, reaching, cooking, talking, and so on. This is why the 'quiet standing' protocol that has dominated the study of postural control has been criticized as an ecologically invalid generic exemplar of standing posture. In sum, there is often a relevant frame of reference to motor skills that is beyond the movement pattern and the outcome.

Movement Patterns. Wickstrom's (1977) early account of fundamental movement patterns gave emphasis to the attainment and progression of the movement pattern with development of the child. In terms of today's dynamical accounts of motor control, it emphasized the space-time kinematic qualitative (topological-McGinnis \& Newell, 1982; Turvey, 1990) properties of the fundamental movement patterns. Wickstrom (1977) focused on the development of motor skills in early childhood (3 8 years) and in doing so made little connection to movement generalization from the infant (birth $\sim 2$ years) motor development sequence and its antecedents or to the later subsequent periods of middle childhood $(9 \sim 11$ years $)$ and adolescence $(12$ 18 years). Here, given the paper's focus, we only distinguish infancy (birth $\sim 2$ years) from the remaining continuous age range of child development (2 18 years).

Wickstrom's book (1977) was published before the widespread availability of motion capture systems and the movement description provided was largely drawn from natural observation. This strategy has since been shown to be largely valid and reliable for the qualitative issues that were addressed in motor development. 
Given the above, it follows that Wickstrom (1977) emphasized movement patterns of the torso and limbs that were the goal of the action (walking, running, jumping, throwing, catching, galloping, skipping, climbing) rather than, or in addition to, the outcome (distance thrown, time of run, etc.) from the respective movement pattern. The title and content of the Wickstrom (1977) book holds these activities as the fundamental motor skills. More recently, McManus (2010) has broadened this working list of fundamental movement patterns to include any new movement pattern, presumably as intuitively and informally defined by topological spacetime properties of the movement.

Movements. The biomechanical orientations to the description of fundamental movements are also focused to the core dimensions of movement patterns without the intentional goal-oriented constraint central in the fundamental motor skills label. For example, Chek (2014), a leading individual of the strength and conditioning domain, has proposed that there are just seven fundamental movements: locomotion, hinge, squat, anti-rotation, rotation, push, and pull. This list of seven movement categories also matches the working principles of the chiropractic profession (Activechiropractice.com, 2016) as to what are fundamental motor skills. However, it should be recognized that we can find advocates for six, five, and any other number of fundamental motor skills.

In a dynamic movement approach, Hogan and Sternad (2012) have proposed that three primitives form the basis of movement in the wide range of actions that we engage in. The movement primitives are submovements, oscillations, and mechanical impedances that can be simultaneously and sequentially combined to produce observable forces and motions. It was argued that encoding in terms of parameterized primitives may be an essential simplification required for learning, performance, and retention of complex skills.

The use of the term fundamental movements, therefore, reflects a different frame of reference than that of the termfundamental motor skills. The focus is the movement properties (typically biomechanical) without an overarching consideration of realizing a movement goal or functional need other than the identified restricted movement property. Thus, fundamental motor skills is the more general and inclusive label and the one adhered to in the remainder of the paper.

\section{Task Constraints and Neuromuscular Mechanisms are Distinct Categories of Control}

There have been two predominant approaches to identifying fundamental motor skills and classifying motor skills more broadly: namely, analysis and interpretation of the outcome of the action, and/or the related movement pattern. The former, like much of the behavioral movement literature, emphasizes the functional outcome or the task demands of motor skills. The latter is consistent with the Wickstrom (1977) analysis of motor development and the determination that the kinematic features of the movement pattern characterize a fundamental motor skill. Of course, both approaches to motor skill classification can be invoked in a complementary way.

One behavioral outcome framework for classification of fundamental motor skills is that of the functional goal or task demands of a motor skill. From this perspective the categories of posture, locomotion, and object-interaction are often 
used in the context of children's motor development. Hence, the identification of general action categories at the task level with the functional goal: posturemaintenance (static and dynamic) of postural orientation and equilibrium (Horak \& Macpherson, 1996); locomotion-movement or the ability to move from location A to location B (Haywood \& Getchell, 2020); and object-interaction (all forms including prehensile, ballistic, and manipulative skills; Haywood \& Getchell, 2020).

The primary functional characteristic that defines each of these fundamental motor skill categories is distinct and independent from the other two categories. For example, the locomotion transport task characteristic is essentially the opposite of the static equilibrium posture task characteristic. Interacting with an object to achieve a certain goal is a distinct task constraint from the basic task function of transporting from location A to location B. Thus, there can be distinct fundamental motor skill categories even when the same neural-muscular mechanism of control is being used across tasks, such as in postural support.

This interpretation of fundamental motor skills seems counter to the general assertion, for example, that posture is involved in all actions including those of locomotion and object-interaction. Indeed, many motor skills seem to integrate components from all three functional task categories. For example, throwing a javelin minimally involves running, postural support, and object projection. This analysis is, however, not uniformly at the task level of description; indeed, the claim of the ever presence of posture involves a subtle change of level(s) of discussion from that of task constraints to that of mechanisms of motor control. The task and mechanism levels of observation and analysis need to be distinguished without conflation in the effort to unpack what is fundamental about fundamental skills.

It is at the task level of analysis that the goal(s) and possible rules or explicit constraint(s) on the movement pattern of the action provide an umbrella-like constraint on movement organization and the search for a motor solution to the task demand of the skill (Newell, 1986; Newell \& Jordan, 2007). The sources of task constraint coalesce with those of the environment and the individual in providing boundary conditions to the solving of what Bernstein (1967) has called the motor problem. The task level of analysis provides the primary leading level of constraint in this framework as it is the goal of the action to be realized around which the perceptual-motor systems are organized. The construct of posture is only defined as a parallel task goal construct to that of locomotion or object-interaction tasks when postural equilibrium or orientation is the primary goal of the task, as in the quiet standing protocol. In the javelin throwing example the role of posture is functional as a neural mechanism of control but secondary to that of the primary task demand: namely, projecting the javelin the greatest distance within the rules of the athletic event as the task constraint.

The distinction of task constraints and mechanisms of motor control is explicitly recognized in the multi-level framework of Bernstein's $(1947,1996)$ construction of movements. The framework has the neuromuscular organization at five levels of the system (Tonus, Synergies, Space, Action, Symbolic Coordinations) that are influenced by the goal of the action (task constraint) in question. Each level of the construction of movements holds a key role to solving a particular class of motor tasks. In the Bernstein (1947) theory, each motor task discovers for itself, depending on its content and semantic structure, one leading level of construction that can change or switch according to the task constraints. The 
bigger picture of this mapping of perceptual-motor skills to Bernstein's levels of construction is the potential development of a task taxonomy that is grounded in a functional and structural neuroscience of the central and peripheral nervous systems. Bernstein (1947), in effect, brought the task constraints into the foundation of his theory of motor learning and development.

\section{Classifications of Fundamental Motor Skills}

The major approaches and orientations that have used the construct of fundamental movement skills are now considered. There is a phylogenetic source of variance to the onset of human bipedalism and other fundamental motor skills (Stanford, 2003). Nevertheless, the primary emphasis to fundamental motor skills has been developmental (ontogenetic) and the mapping of chronological age (CA) to the emergence of a given motor skill (e.g., Shirley, 1931). This analysis is done on an individual child basis but typically and problematically the data are presented on an averaged age-group basis. The notion of fundamental motor skills has also been approached through phylogenetic and ontogenetic principles of adaptation and learning in motor development including the influence of cultural context (Adolph \& Hoch, 2019; Bril, 2018; Super, 1976; Thelen \& Smith, 1994). There is also an applied task-oriented emphasis to the dynamics and progressions of the developmental change to the fundamental motor skills (Seefeldt, 1980; Wickstrom, 1977).

The outcome is that the definitions and classifications of fundamental motor skills have emphasized different combinations of their time scales of influence: namely, evolutionary (phylogenetic), developmental (ontogenetic), biological (local dynamics), and task (goal) in the confluence of constraints on action (Newell, 1986). The science orientation to motor development gives recognition to all four of these categories of constraint even while emphasizing a subset of the problem. Whereas the applied practical orientation to movement and skills tends to ignore the evolutionary influence while emphasizing ontogenetic and task contributions to fundamental motor skills. The local dynamics are the province of motor control that usually does not consider the time scales of the change over time focusing, rather, on the time scales of the dynamics of local system oscillations.

\section{The Evolutionary Influence}

It is hard to think of a motor skill more fundamental than that taken to help define the origins of the human species. But, this is the special case for bipedal standing and locomotion. The transition of chimpanzees' four-legged gait to the bipedalism of a hominid has been the focus of considerable investigation of the history of human kind by scholars from a variety of biological and cultural disciplines. The received view is that the transition to upright took place about 6 million years ago and is the evolutionary key to becoming human (Stanford, 2003). Indeed, humans are the only mammal to engage bipedalism as the primary mechanism of posture and locomotion. It follows that the development of upright standing and the subsequent progressions to walking and running have been labeled as fundamental motor skills in that it is taken that a near universal percentage of the healthy cohort group of infants exhibit this sequence in the emerging of movement patterns. The fundamental activities of sitting, standing, walking, running, and prehension not 
only precede the emergence of other motor skills but by definition originated with the human species.

The transition to being upright, it is generally assumed, opened a number of associated functional benefits to the hominid (Stanford, 2003). Bipedal locomotion made transport over rougher terrain and longer distances more realizable. Furthermore, the evolution of running and with it the enhanced speed of transport provided multiple adaptive consequences for the evolving homo species (Bramble \& Lieberman, 2004; Carrier, 1984). Bipedalism also freed the upper-limbs for other purposeful and adaptive activities including food gathering, making tools, throwing, and the warding-off of predators more generally (Dunsworth, Challis, \& Walker, 2003). Thus, on a number of grounds, the development of a range of prehensile and object manipulation activities is a hallmark human attribute of fundamental motor skills (Marzke, 2013).

The continued expansion of activities conducted with arm-hand coordination is assumed to have been facilitated by the increasing size of the hominid brain and the evolving neuro-anatomical structure. These adaptations are background to the current sophisticated fine movement in action of the eye-brain-hand complex, such as that exhibited by a neurosurgeon. More generally, the increase in brain size is linked to the development of intelligence and planful behavior in the evolution of Homo sapiens.

This brief outline on the role of movement and action in the development of the human species should be sufficient to show that a case can be made for standing, walking, running, and certain forms of object-interaction (prehensionreaching and grasping) to be the fundamental motor skills. They are fundamental not only because they are the basis of human movement in distinct classifications of action functions but also because they emerged before the development of the many ontogenetic motor skills that develop in childhood and to a lesser degree in adulthood. They are also fundamental because they are broadly integrated into other action categories thus supporting their widespread transfer and generalizability. These early and specific actions map to the contemporary and general functional task activity categories emerging of posture, locomotion, and objectinteraction. Moreover, it would be anticipated that the fundamental motor skills are typically the most prevalent movement skills performed every day, but data are required on this decomposition of the daily movements and actions of population groups. Anthropology has not gone beyond these basic motor skills to describe or infer about the many transition states and configurations that are realized between their emergence (cf. Sands \& Sands, 2010), such as there is in the infant motor development sequence (Bayley, 1936; Gesell, 1929).

\section{The Developmental Influence: Fetal Motor Development Sequence}

A consequence of the previous movement-related definition is that not all observed movements will be taken as reflecting goal-oriented motor skills or actions. An example is the emergence of fetal movements (de Vries, Visser, \& Prechtl, 1982) where the intentional goal-oriented aspect of the movement is difficult to discern. Nevertheless, the order of the emergence and progression of fetal movements of segments of the body holds some parallels in the direction in development of the 
fundamental motor skills emergent in infancy (Hadders-Algra, 2010; Prechtl, 1986). These general movements of the fetus are precursors of the fundamental motor skills but they are not fundamental motor skills in and of themselves. Indeed, spontaneous movements and reflexes characterize the fetal stage and very early days of neonate motor development.

\section{The Developmental Influence: Infant Motor Development Sequence}

A long-standing view of developmentalists is that the fundamental motor skills are those that emerge during the early developmental stage of infancy (birth $\sim 2$ years). The classic studies of Bayley (1936), Gesell (1929), McGraw (1943), Shirley (1931), and others described in detail the progression of the 'fundamentals' or 'milestones' of motor development in infancy. These traditional accounts, driven by contrasting theoretical dispositions of the maturation vs learning contrast, still provide the descriptive foundation to our understanding of the emergence of fundamental movement skills in infant motor development (cf. Haywood \& Getchell, 2020; Sugden \& Wade, 2013).

That the infant motor development sequence progresses near universality in a relatively invariant order although with variable timing in biological age (BA) and chronological age (CA) continues as a contemporary view (Adolph, Berger, \& Leo, 2011; Adolph \& Franchak, 2017; Bril, 2018; Thelen \& Smith, 1994; Touwen, 1976; Van der Geert, Savelsbergh, \& Van der Maas, 1999, WHO Multicentre Growth Reference Study Group, 2006), albeit under different theoretical frameworks from the early infant studies. Figure 1, adapted from the classic study of Shirley (1931), shows the average chronological time course of the emergence of the onset instantiations of postural, locomotive, and manipulative actions during infancy. Relatedly, Touwen (1976) found that the inter-infant variability of the timing (CA) of skill onset increased more for those skills that emerge later in infancy (see Hadders-Algra, 2010). These observations, taken as a collective on the sequential progression of infant motor development, have provided additional evidence that the fundamental motor skills are core examples of the general action categories of posture, locomotion, and object-interaction.

An essential criterion for a fundamental motor skill to be a precursor for another subsequently learned motor skill is clearly evident in the development of postural tasks in infancy. The potential of postural progression from lying down to upright standing shown in Figure 1 reveals a relatively invariant order that is consistent with (though not proof of) the notion of the antecedent role played by sequential emergence of postural tasks. The percentage of departures in the cohort from this order in the form of reversals, omissions, and co-missions is not understood, but it is assumed generally to be very low in occurrence, thus affording the near universality inference to the infant motor development sequence. Notice too that squatting is not usually listed as an infant fundamental motor skill though it is common practice in a number of other cultures.

Of course, much depends on the population pool chosen to reflect the universal construct. The most relevant to match the near universal term would be all healthy children on a world-wide basis within a selected age and cohort group. And, while we do not have large data sets on how close nearly universal is in this context it is 
also the case that we do not have large sets of data showing violations to the standard sequence. The limited evidence on sequence violations suggests that creeping and crawling may be the most susceptible to order departures of one kind or another from the normative listing, but the probability of these events and other departures is not known.

In the last 50 years there has been a growing number of cross-cultural studies of infant motor development in general and the fundamental motor skill sequence in particular. These studies have shown that the culture-specific way that families and in particular mothers raise their children (e.g., handling practices) can influence the order and/or timing of the emergence of the fundamental motor skills (cf. Bril, 2018; Bril \& Sabatier, 1986; Super, 1976). These findings confirm the importance of recognizing the potential and actual impact of brain plasticity and the place of context in motor development, together with the emergence of the fundamental motor skills.

The role of constraints on infant motor development and its lasting effect on individual development is also evident in the linking of the configuration of infant sleeping postures to Sudden Infant Death syndrome (SIDs) (cf. Majnemer \& Barr, 2005; Oriel, Frazier, Lebron, Pinkerton, \& Townsley, 2006). The supine posture of the infant lying on the tummy was found to be related to SIDs and this led to the recommendation for the infant to be placed prone (lying on the back) to go to sleep. The implementation of this American Academy of Pediatrics recommendation did reduce the incidence of SIDs but it also surprisingly led to an enhanced prevalence for delays in the emergence of the fundamental motor skills. This outcome provides another example of the effect of cultural practices, in this case prescribing the sleeping configuration in the first year of life, on the emergence of the motor milestones (timing and occurrence).

A long standing and still held view is that the order of emergence of the infant motor sequence reflects the general and traditional maturational concept of development being in an anatomical cephalo-caudal (head to tail) direction, along with proximal-distal and ulnar-radial directions (Bayley, 1936; Gesell, 1929). This principle of developmental direction as Gesell (1952) called it has, however, not been tested sufficiently under a wide range of task constraints to action so as to examine more systematically the order to the emergence of the fundamental motor skills under different conditions (Newell \& van Emmerik, 1990). The experimental tests of developmental direction are also challenged by the different interpretations of cephalo-caudal (namely: head to tail; head to foot [toe]). Cauda is the Latin for tail. Cephalo-caudal as head to tail provides that the legs are with the arms as proximal-distal.

The sequential development of upright postural control may provide the strongest evidence in motor development of the antecedent role of fundamental motor skills. The order of the emergence of the control of head orientation to torso control of sitting to the whole-body control of upright standing is afforded by the unfolding neuromaturation of infant growth and development and constrained by the physics of the movement in action situations. Largo and Kakebeeke (1994) indicated that before the infant can purposively use his hands at the age of about 5 months, the following prerequisites need to be fulfilled: coordination of head and eye movement as well as coordination of head/eye and hand movements.

Moreover, young infants cannot sit stably without being able to stabilize head control (e.g., Bertenthal \& von Hofsten, 1998), and supporting the head and torso 
in sitting facilitates the onset of reaching and grasping in infants (Bullinger, 1990; Grenier, 1981; Rochat, 1992). In the same way, infants cannot stand without being able to control head and torso posture. And, infants cannot run before they can walk due to the need to learn to control the potential instability of the falling segment of running that destabilizes the walking gait and that opens the situational constraints to the movement pattern of running.

These sequential trends in infancy of the development of posture are strong evidence for the construct of posture as a fundamental motor skill. It is important to re-emphasize, however, that the claim of near universality of order in postural development is observational, descriptive, and inferential, it is not the product of direct experimental measurement. Nevertheless, given also that posture is 'in' all movement actions and categories, including the specific movement skill classes of locomotion and object manipulation, the case can be made that posture is the most fundamental or central motor skill. Gesell (1952, p. 65) put it this way: "Much of the embryology of behavior can be interpreted in terms of posture. The human action system is a postural system" (see also Adolph \& Franchak, 2017). This perspective on the primacy of the role of posture (or locomotion and objectinteraction as emphasized), however, tends to conflate the task versus mechanism levels of analysis distinction discussed previously. Life would also be functionally restrictive prohibitively if posture was the only task category.

The emergence of the postural patterns illustrated in Figure 1 reflects the major postural coordination patterns. However, the figure does not show the range of intermediate configurations and movement patterns produced by the infant in the process of developing even the fundamental motor skills. For example, Bayley (1936) described the often many steps and phases of the emergence to each of the infant motor skills. One of the more well-known intermediate action examples is 'cruising', where the infant between standing and walking supports him or herself by hand contact with objects (chairs, tables, etc.) to transport via supported walking in the environment. Cruising is another example of infant postural support facilitating execution and performance of other action categories (Adolph et al., 2011).

The widely held proposition that the fundamental categories of motor skills are posture (equilibrium and orientation), locomotion, and manipulation does not mean that all skills in these categories are fundamental motor skills. There are, for example, locomotion skills such as heel to toe walking that are difficult to consider as fundamental due to their not being near universal in the cohort, a significant precursor to other motor skills, and their marginal presence in the daily life of most individuals. Parallel arguments could be made for objectinteraction tasks and to a lesser extent the postural support category. Thus, there is a distinction between the general fundamental action categories of posture, locomotion, and object-interaction considered at the construct level and the particular operational motor skill exemplars of that respective category. This implies that the unpacking of what constitutes fundamental motor skills needs to be at the more generic activity frame of reference as well as that of the particular exemplar motor skill level.

Infancy, then, is characterized by the continued and progressive development of the fundamental motor skills: namely, postural control through to sitting (erect trunk), upright standing, walking and running, and the basic prehensile (object- 
interaction) skills of reaching and grasping. The acquisition of this small set of fundamental motor skills in infancy holds a number of unexamined parallels to the early stage of adult motor learning that Fitts (1964) and Gentile (1972) viewed in a cognitive interpretation as 'getting the idea of the task'. In a dynamical framework, the early stage of learning is characterized by the search for the formation of the task-relevant coordination pattern and the emergence of the collective variable for the task (Mitra, Amazeen, \& Turvey, 1998).

\section{Movement Patterns in Childhood and Adolescence (2 18 years)}

While the fundamental movement patterns of posture, locomotion, and objectinteraction emerge in infancy, the subsequent years of growth and development through maturation together with the experience of movement practice from engaging actions in context, channel continuous adaptive influences on the movement pattern and outcome of the emerging motor skills (Adolph \& Francak, 2017; Thelen \& Smith, 1994). Indeed, a substantial biomechanics/motor control literature shows that there are continuous adaptations to posture, gait, and object-interaction motor skills through the life span (Haywood \& Getchell, 2020; Shumway-Cook \& Woollacott, 2016). The broader lifespan view of motor development provides for a dynamic landscape of continuous and discontinuous change in the movement patterns of perceptual-motor skills (Newell \& Liu, 2014; Newell \& Morrison, 2016).

Figure 2 shows a schematic originally from Muchisky, Gershkoff-Stowe, Cole, and Thelen (1996) revised by Thelen and Smith (1994) that is an elaboration of Waddington's (1957) epigenetic landscape for development. The schematic represents the dimensions of developmental time, the capacity for physical activities (as identified on the horizontal axis of the figure by collective variables), and their stability (depth of well). The figure presents an image as metaphor of the continuities and discontinuities of the movement forms of infant development as shown behaviorally by Figure 1. It captures the flow of the qualitative and quantitative change in the dynamics of development and the emergence and dissolution of movement activity patterns (labeled here as collective variables). The schematic of Figure 2 could be extended in developmental time to include the acquisition of the movement activities beyond infancy and to show the dynamics of change (including behavioral decline) across the lifespan to death (Newell \& Morrison, 2016). Importantly, the landscape of Figure 2 implies continuity and discontinuity in the emergence of motor skills confirming that our time scale divisions of phylogenetic/ontogenetic and chronological age for analysis are primarily conveniences of description.

There are, however, limitations to the logic and veracity of the developmental landscape schematic as presented (Newell, Liu, \& Mayer-Kress, 2003, 2009). Figure 2 shows more than a single activity being stable at any developmental time point. Behaviorally this is not possible and thus the figure represents a potential of a collective variable to be stable at a developmental time point rather than the actual dynamics of movement that are realized at any moment in time. The landscape as potential also, however, does not capture the influence of the initial conditions and intrinsic dynamics on the emergence of any movement pattern. The schematic shows on the horizontal axis an order to the particular activities 
Ontogenetic Landscape for Locomotion

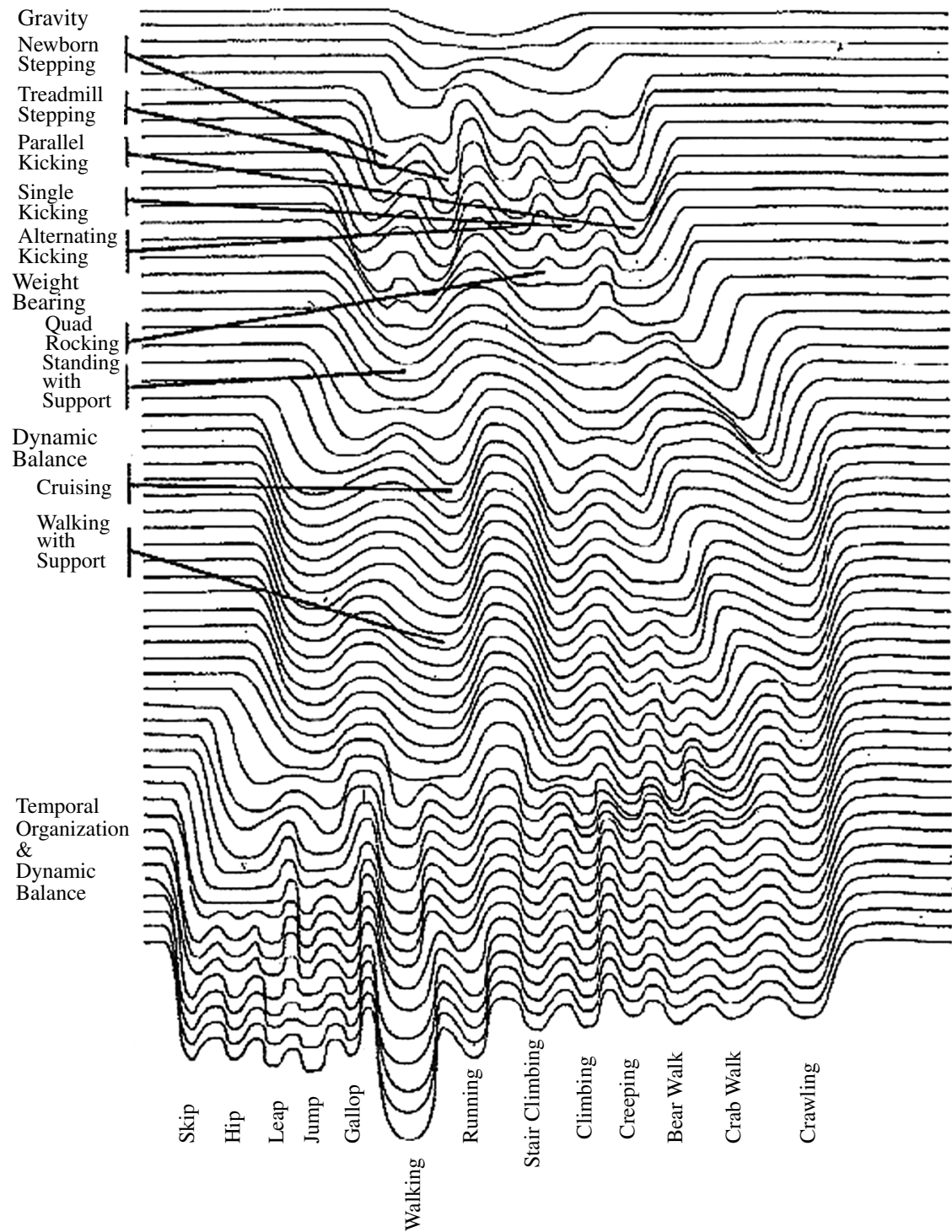

Figure 2 - Multiple time scales of development. This figure depicts an elaborated form of Waddington's landscape. Adapted by Thelen and Smith (1994) from Muchisky et al. (1996).

(labeled originally collective variables in the Muchisky et al., 1996 version), but this is essentially arbitrarily based as to the similarity of the activities. The assumptions here are at the heart of the challenge of understanding the 
development and generalization of the fundamental motor skills through the life span (see also Thelen \& Smith, 1994).

There have been many categorizations of the influence of developmental age beyond infancy on the acquisition of motor skills (see for e.g., Haywood \& Getchell, 2020; Sugden \& Wade, 2013; WHO Multicentre Growth Reference Study Group, 2006 for recent examples). Table 2 shows a selection from these sources of motor tasks in the 2- to 18-year-old range that are often designated as fundamental motor skills (see also Wickstrom, 1977). They are listed under the categories of posture, locomotion, and object-interaction to provide continuity to the 0-2 years categories of the fundamental motor skills. These are movement patterns and functional tasks that all emerge in this developmental time period, but in the context of this paper the central question is are they fundamental motor skills?

The key to moving forward on categorization is adhering to the definition of a fundamental motor skill and drawing on that as to how one assesses a motor skill to be of fundamental status. Having a standard unifying strategy on this matter becomes more pressing given that there are also taxonomies with an even larger pool of designated fundamental motor skills (e.g., Seefeldt, 1980) than listed in Table 2.

As an example of the challenges of classification, it is useful to consider how swimming should be categorized - sports skill, activity of daily living, or fundamental motor skill? There are certain cultures where swimming is seen as an essential skill that children should become proficient at. The school systems of a number of western societies and cultures have dropped learning to swim from the working fundamental list or the school physical education lesson. This is in spite of the continuing preservation of the neonate swimming reflex and the skill of swimming to have potentially life-saving capacity.

Collectively, the early childhood through adolescent years from age 2 18 lead to a remarkable progression of developmental changes that influence the prevalence of particular movement patterns and actions, together with the learning and performance of an increasingly larger individual repertoire of motor skills. An obvious development beyond infancy is the change in movement skill through the growth of children over this time period both at the macro level of height and weight but also at the biological systems levels of the human organism, including perceptual-motor. Growth itself influences motor development and engagement in motor skills in turn has a reciprocal influence on growth (Newell \& Wade, 2018).

There is a probabilistic structured progression of developmental changes that influence the emergence and prevalence of particular movement patterns and actions (Kugler, Kelso, \& Turvey, 1982; Thelen \& Smith, 1994), together with the learning and performance of an increasingly larger repertoire of motor skills with advancing age. The hypotheses that follow are drawn from the position of a stronger experiential influence on the motor skill repertoire the older the child (Touwen, 1976). It would be anticipated that:

(i) the regularity to the order and timing of the emergence of new motor skills after infancy will be less than that observed for the fundamental motor skills of the earlier infant motor development sequence;

(ii) the later in developmental age the motor skill emerges the more likely it is that there is enhanced variability in the cohort group to the onset time of the skill in question, including potentially the skill not being evident at all; 


\section{Table 2 Core Developmental Activities That are Often Interpreted as Fundamental and That Emerge in Early and Middle Childhood}

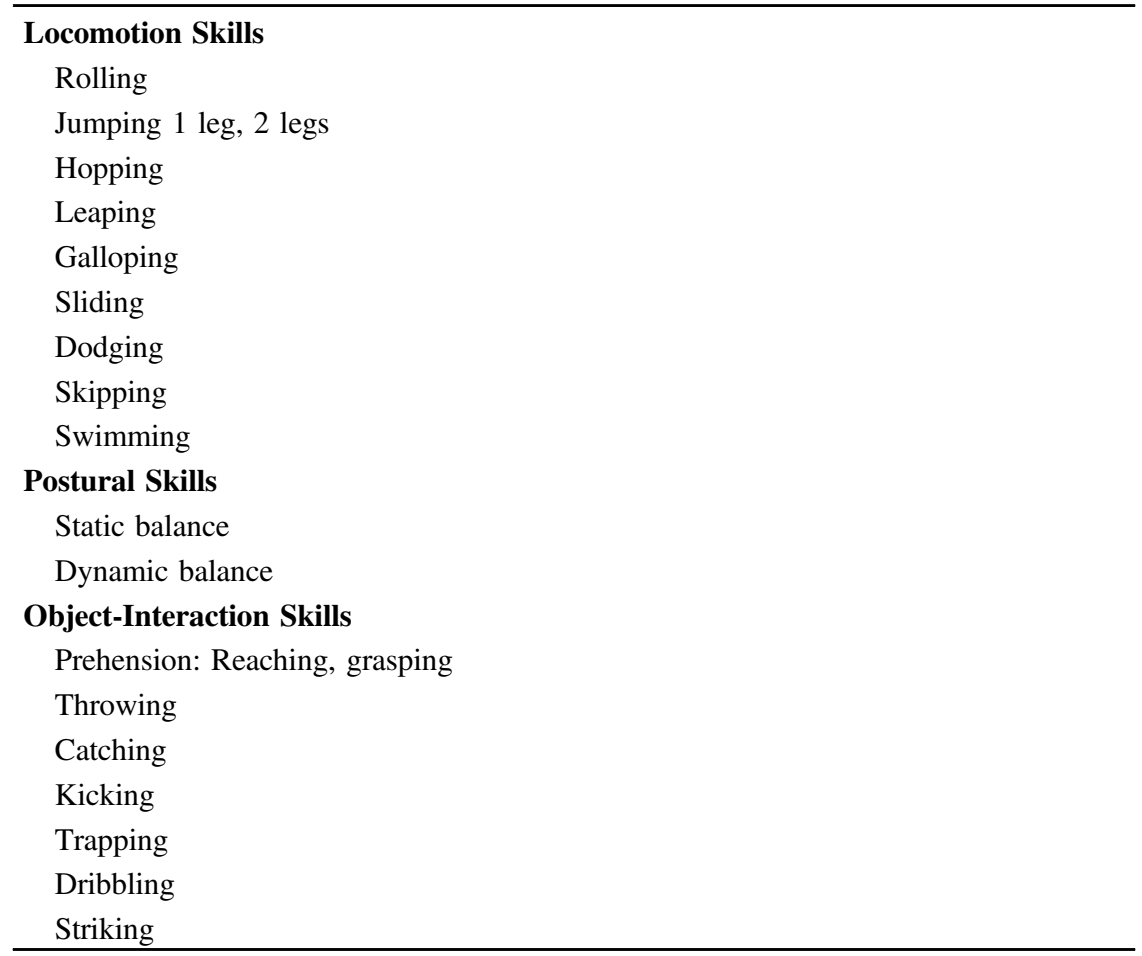

Note. Lists drawn largely from Haywood and Getchell (2020).

(iii) there will be a lower probability than the sequential postural development in infancy that an invariant order to the onset of motor skills is preserved; and

(iv) the more variable the timing of skill introduction between children in ontogeny the less likely the skill is a fundamental motor skill.

There appear to be no major experimental tests conducted of the above hypotheses regarding the changing probabilistic structure of the development of children's motor skills beyond the infant motor development sequence. Figure 2 shows a schematic from the Western Australia handbook on fundamental motor skills of the kinds of data hypothetically that are required to investigate the probabilistic nature of the acquisition, retention, and transfer of motor skills as a function of age in childhood. It shows the non-linear nature of the timing of the introduction of a set of skills through to their mastery (Table 3).

To illustrate this set of assumptions and hypotheses on the timing of learning new skills in early childhood, a more detailed look at the skill of overarm throwing is made (candidate fundamental motor skill) and the variability profile of its sequential development will be examined. In the same way that there is a relatively invariant order to the unfolding of the infant motor development sequence and to some other motor skills of the 2- to 18-year-old range, there is also some regularity 


\section{Table 3 Example of Relation Between Introduction (Intro) and Mastered (Mast) Time Course of Selected Motor Skills Beyond Infancy}

\begin{tabular}{lllllll}
\hline Fundamental Motor Skill & Prep & Year 1 & Year 2 & Year 3 & Year 4 & Year 5 \\
\hline Catch & Intro & & Mast & & & \\
Kick & Intro & & & Mast & & \\
Run & Intro & & Mast & & & \\
Vertical Jump & Intro & & Mast & & & \\
Overhand Throw & & Intro & & & Mast & \\
Ball Bounce & & Intro & & Mast & & \\
Leap & & Intro & & Mast & & \\
Dodge & & Intro & & Mast & & \\
Punt & & & Intro & & Mast & \\
Forehand Strike & & & Intro & & & Mast \\
Two-hand Side-arm Strike & & & Intro & & & Mast \\
\hline
\end{tabular}

Note. Adapted from Western Australia Handbook.

and order to the emergence of the progressions of the throwing movement pattern within the acquisition of the respective motor skill. Outside of standing, walking, reaching, and grasping there have probably been more experimental studies on the development of 2- to 18-year-old children's overarm throw than any other motor skill.

As was noted previously throwing has typically been interpreted as a fundamental motor skill that held several functions (food gathering, holding off potential attackers, etc.) all related phylogenetically to adaptive survival characteristics. However, babies certainly throw objects, particularly food, during meal times; but typically this throwing motion and its outcome goal is not the overarm throwing pattern that has been seen as central in motor development. The question of which movement pattern best represents a given action class is an open issue that we examine more closely later in the paper.

Wild (1938) conducted an early experiment on an overarm throwing task but it is the more recent studies of Roberton and colleagues that have provided analysis on the probabilities of sequential coordinative states in the development of overarm throwing (Roberton, 1977; Roberton \& Halverson, 1984). Based upon high-speed film analysis of young children (6, 7, and 8 years old, boys and girls) learning the overarm throw, Roberton developed a components model of the change in throwing motion over practice time. The components were subunits of anatomical coordination such as arm, leg, and trunk motions, and rating scale observations determined the contribution of each component within a throwing trial. The findings showed the importance of the leg and trunk motions to the development of the arm throwing action. Learning to coordinate the arm throw with the trunk rotation and leg step seems to be the challenge for the learner.

Of particular relevance is the conclusion that the "development within component parts may proceed at different rates in the same individual or at different rates in different individuals" (p. 55). This statement captures one of the 


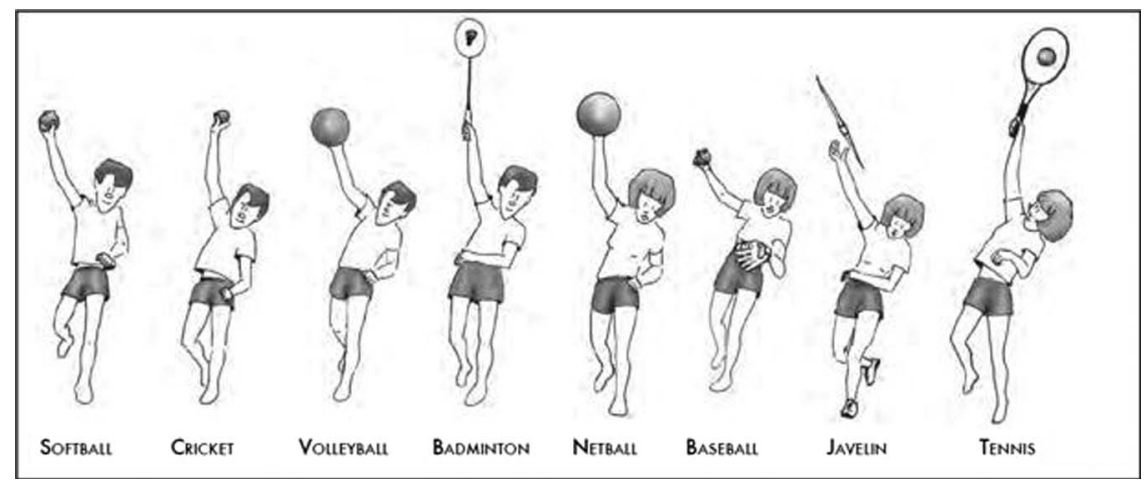

Figure 3 - Relationship between fundamental motor skills and specific sports skill (overarm throw). Adapted from State of Victoria, Australia (1996) handbook on fundamental motor skills.

challenges in assessing the competence in motor skills both of individual children and comparing between children past and present.

Figure 3 shows movement patterns (configurations) for a range of motor skills that have been interpreted to have a similar basic arm action to that of the fundamental motor task of overarm throwing and that would be facilitated by generalization from the overarm throw. The critical overarm defining configuration properties do look similar at first glance as if they will provide generalization across tasks, but we need more than just face validity of static kinematic images to formally test ideas of transfer in the context of fundamental motor skills. The other components of throwing may differ more across the sport examples of Figure 3 than the arm motion itself. Principal component analysis could be implemented to reveal the degree of commonality of component structure across the different throwing-like activities shown in the figure (Daffertshofer, Lamoth, Meijer, \& Beek, 2004).

\section{The Seefeldt (1980) Pyramid Taxonomy}

Seefeldt (1980) proposed what is the most comprehensive taxonomy of motor skill development from birth through to adulthood (see Figure 4) that has also been a resource for several other taxonomies. The pyramid presentation captures the idea of motor skills at different levels of development (neonatal through childhood to adulthood) being antecedent building blocks for subsequent development of new motor skills. The age continuum is proposed to correlate modestly with the progressive exhibition of children's movement attributes: reflexes, reactions; fundamental motor skills; proficiency barrier; transitional motor skills; specific sports skills and dance.

There are 28 fundamental motor skills listed by Seefeldt (1980), which is perhaps the largest listing of fundamental motor skills though it includes many of the same items classified in other taxonomies such as those listed from Haywood and Getchell (2020). The pyramid list also contained the essence of the standard fundamental motor skills list of infants that were previously discussed. Seefeldt 
provided little or no rationalization as to why each skill warranted the status of being fundamental; hence, it is hard to appreciate the validity of all of the choices even though they seem to reflect unique movement patterns. The appropriateness of and need for the transitional motor skills category together with the proposed exemplar activities also deserves a thorough re-examination. The face validity of several of these transitional skills for the complex sports skills listed seems questionable at best.

Seefeldt (1980) introduced the idea of a proficiency barrier to the transitional and complex skills of sport and physical activity that needed to be crossed by the developing child so as to be successful in the ultimate sports skill of interest. The barrier reflected a general level of competency in the fundamental motor skills that was taken as necessary to be successful in learning the more complex activities of sport. Seefeldt's (1980) approach also rests on a widely held assumption: namely, that competence in the fundamental motor skills provides subsequently a broad degree of generalization to more complex activities. Again, the emphasis on the

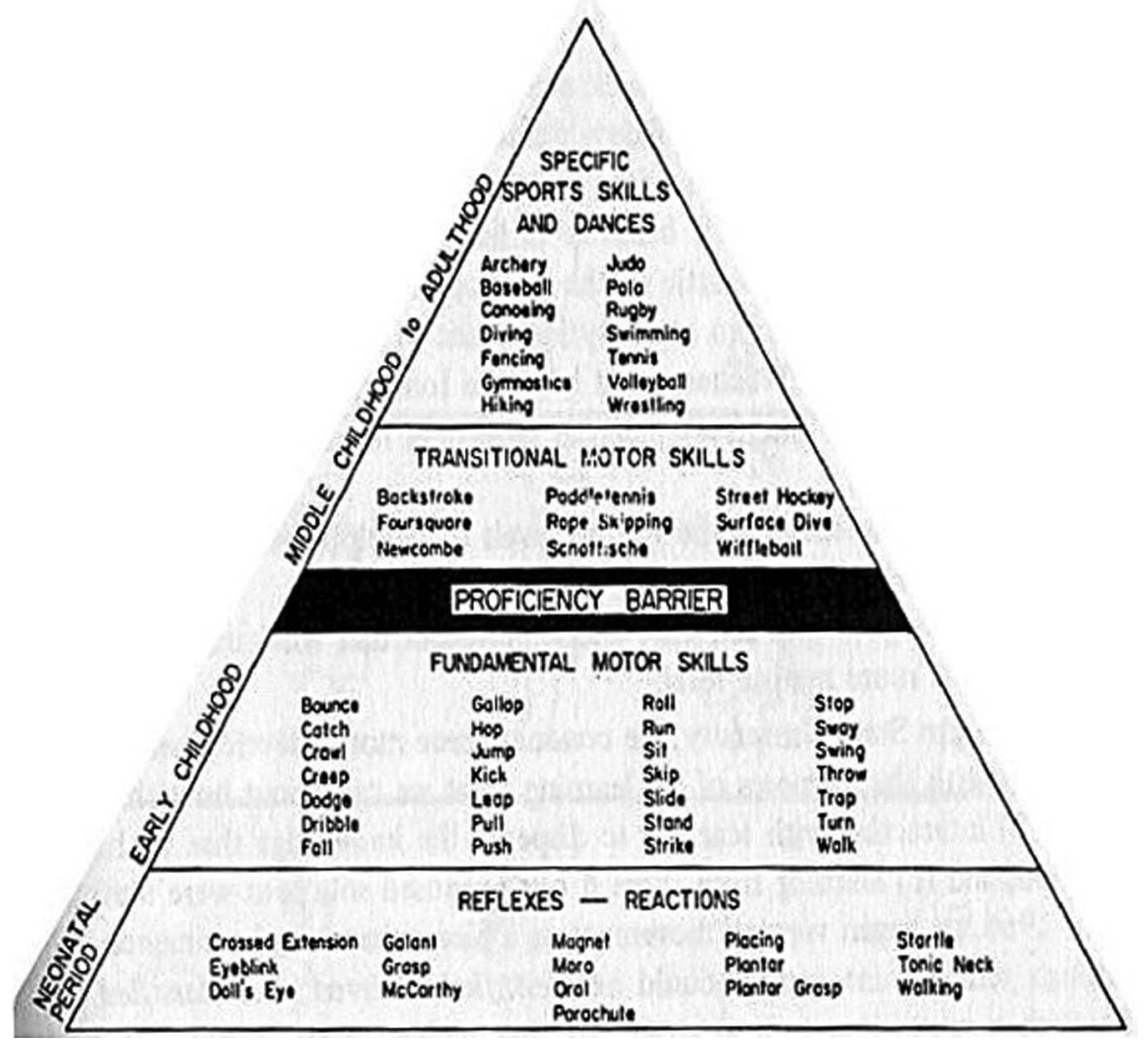

Figure 4 - Adapted from Seefeldt (1980) Pyramid taxonomy of fundamental motor skills. 
fundamental motor skills here is the pathway of skill progression to actual sport skills and physical activity more broadly.

\section{Other Examples}

In a government example, the State of Victoria, Australia (1996) handbook lists 11 of what are called critical fundamental motor skills: catch, kick, run, vertical jump, overhand throw, ball bounce, leap, dodge, punt, forehand strike, and two-hand sidearm strike. These designated fundamental skills seem relevant for certain sports but several do not form the necessary generic basis one would expect from fundamental motor skills. And, as an aside, the phrase critical fundamental motor skills implies that there are noncritical fundamental motor skills that could be classified!

A final observation on the precursor/antecedent role of fundamental motor skills is that the to-be-learned more complex skills are typically from the physical activity and sport domain; yet the same effort to characterize generalization could be made toward other motor skill contexts including activities of daily living, communication skills, and self-help skills. The presence of activities of daily living and self-help skills in the scope of possibilities would also lead appropriately to a more tangible place for fine motor skills in the consideration of what is a fundamental motor skill and what makes a person physically educated. Finally, a broader activity view would also contribute to forming a lifespan framework for measuring competence and skill in the full range of motor skills including activities of daily living, self-help, and communication skills.

\section{Inferences From the Review and Synthesis of Fundamental Motor Skills}

Here is a list of key observations that are drawn from the review and synthesis of the major approaches to fundamental motor skills. These observations provide direction for the criteria in drawing up a classification scheme for fundamental motor skills.

1. The relevant classification literature of fundamental motor skills has not sufficiently adhered to the meaning of the word fundamental by including what constitutes fundamental in the motor skill context. In the extreme, every unique movement pattern has been classified as fundamental.

2. There has been no theoretical position developed as to what it means to be fundamental in the motor skill context.

3. The idea of fundamental motor skills providing the building blocks for the subsequent learning of new motor skills in different context is the common position from most scholarly orientations to the problem, but is generally poorly rationalized. There is no conceptual development or experimental evidence of generalization/transfer beyond isolated observations for fundamental motor skills being building blocks for the subsequent learning of other motor skills.

4. The prototypical motor skills of the task categories of posture, locomotion, and object-interaction formed in infancy capture the major fundamental motor 
tasks. Posture has a strong claim to being the most fundamental and generic motor skill or task category but the distinction between its role as a task goal and as a supporting neuromuscular mechanism to a locomotion or objectinteraction task needs to be preserved. It is the three categories of posture, locomotion, and object-interaction as a collective, however, that provide for a wide range of integrative functional motor skills.

\section{Toward a Classification of Fundamental Motor Skills}

Some understanding and theoretical framework for handling these descriptive issues is necessary to approach the central question of this paper as stated in the title. The synthesis presented here reveals two major orientations to the classifying of fundamental motor skills. One orientation is the basic biobehavioral science approach to fetal and infant motor behavior that draws on evolutionary theory, phylogeny, and ontogeny to characterize the fundamental motor skills developed by the neonate and infant. A second orientation reflects more applied research of the development of the fundamental motor skills in primarily school-age children and youths (2-18 years). The consequence is that the different orientations emphasize distinct definitions, different age-related movement phenomena, and theoretical perspectives as to what is fundamental about fundamental motor skills.

It is proposed that the fundamental motor skills of the species of Homo sapiens are the small set of core prototypical infant movement patterns and goal outcomes of upright posture, locomotion, and object-interaction. This classification does not include, for example, in the category of locomotion all gait patterns, rather just the basic generic movement pattern with preferred parameterization of walking and running. The formalities of the operationalization of this classification remain to be detailed.

The fundamental movement skills provide the basis of a broader and larger set of unique movement patterns and skills developed primarily through childhood and adolescence that are labeled here as 'core developmental activities.' The young adult can experience an ever-widening range of movement contexts including dance, exercise, music, play, sport, and work, but it is probably only in music, dance, or sport that the individual adult learns a new pattern of coordination. In this group, as we will see, there are many movement patterns beyond the infant movement patterns that have been proposed as the fundamental motor tasks. These movement skills are important and, in a few cases, may even be fundamental to the organization of more complex motor tasks; but it is doubtful that they are fundamental to the survival of the species and they are not fundamental to the coordination, control, and skill of many given tasks-although in principle they could be at some time in the future.

\section{Fundamental Motor Skills: Essential Features}

A synthesis of these diverse approaches to fundamental motor skills leads to the proposition that whether a motor skill is fundamental is dependent on the collective presence of three conditions, including: (i) the task has a uniqueness to the movement pattern and outcome; (ii) there is near universality in the healthy cohort group of the functional outcome activity; and (iii) acts as an antecedent influence supporting generalization to a large and broad set of related perceptual-motor skills. A formal 
evaluation scheme could be an expert panel constructed to assess the appropriateness of candidate fundamental skills in light of the three criteria for fundamental status. There follows a few notes on each of the three criteria for determining a fundamental motor skill.

Uniqueness of the Movement Pattern and Outcome. The rationale for a task to be fundamental rests on the basic and necessary assumption that the movement pattern and outcome have robust but unique properties that can be characterized and that distinguish it from other activities (McGinnis \& Newell, 1982; Turvey, 1990). Motion capture and kinematic analysis techniques can identify the qualitative and quantitative properties of the movement dynamics that define the task. Some progress has been made in this direction particularly in the fundamental motor tasks of upright standing, walking, running, and prehension, but we are a long way from a complete inventory of perceptual-motor task dynamics.

This criterion of uniqueness is not peculiar to identifying and determining fundamental motor skills but rather is necessary for the identification and labeling of all motor skills. In a sense, this criterion is a necessary feature for the motor skill to be considered subsequently and without which an estimate of both universality and generalization is probably in most cases superfluous.

Near Universality Within the Cohort Group. The progressive sequence to the emergence of the fundamental motor tasks of the infant has been generally interpreted without the relevant evidence as being near universal. The idea that there is a near universality of the fundamental motor tasks for a given healthy population is what provides evidence for the phylogenetic influence on the infant motor sequence. Nevertheless, environmental conditions and cultural practices have been shown to influence the timing of the emergence of the fundamental movement patterns and also to a degree the emergence of the movement pattern sequence itself. It is assumed that the percentage of the population that adheres to the same order of the ontogenetic motor skills being learned will become progressively smaller as the child continues to grow and develop the 'core developmental activities'.

Generalization to More Complex Skills. A prevalent perspective on fundamental human motor skills no matter the basic or applied orientation is that they generalize to provide the building blocks for the full range of other motor skills. This does not mean that any given motor skill from each category of locomotion, posture, and object-interaction will generalize to all other skills. Rather, the fundamental motor skills taken as a collective have units of behavior that will tend to generalize to most motor skills. The generalization of fundamental skills seems intuitive and logical but there are actually very few experimental data, if any (positive or negative), on this issue. There is a need for large scale learning, retention, and transfer experiments in cross-cultural longitudinal studies of large groups of developing children over a range of ages that would provide the basic data for determining the qualitative and quantitative dynamics of children's evolving repertoire of motor skills.

\section{Fundamental Motor Skills in Practice}

Movement is a ubiquitous feature of living systems and human endeavor more generally. This is well reflected in the diverse range of motor task categories shown 
in Table 1A using development and context as organizers of the skill category frames of reference. There must be at least several hundred motor skills that could be placed in a total list of the categories of motor skills. As a consequence, there are inevitably many ways that the fundamental motor skills relate to practical and professional issues of the now interdisciplinary area of motor skills. Here we give emphasis to two substantial and practical areas that draw on the construct of fundamental motor skills: namely, motor skill acquisition and motor skill assessment.

The 'core developmental activities' proposed here are under the contextual emphasis of the so-called whole-body Sports, Games, Dance, Musical Performance, and Play. Parallel classifications of core developmental activities could be made for communication skills, musical skills, and activities of daily living (including self-help skills).

\section{Fundamental Motor Skills and Motor Skill Acquisition}

Our review and synthesis of the fundamental motor skills has highlighted several important areas in motor skill acquisition for future analysis by synthesis, in addition to needed experimental research programs. In general, the qualitative properties of the fundamental coordination patterns and the emergent new skills in motor development could be re-examined in light of the relevant theorizing of the ecological approach to perception and action and the related domain of coordination dynamics (Adolph \& Franchak, 2017; Kelso, 1985; Kugler et al., 1982; Newell, 1986; Turvey, 1990; Thelen \& Smith, 1994). In parallel, a dynamical approach to motor learning and development opens up some new ways to consider instructional strategies for skill acquisition-particularly of new movement patterns. Some research topics that can engage both theory and practice of the fundamental motor skills, core developmental activities, and the culturally promoted adult motor skills are now briefly presented.

The Building Blocks Assumption. Time is overdue for large scale experimental tests of the broadly held assumption that the fundamental motor skills and the core developmental activities are building blocks to the more complex motor skills and physical activities. Longitudinal learning and transfer/generalization tests of the basic building blocks assumption of motor development are required on an international multicultural basis.

Between- and Within-Skill Progressions. The generalization of the fundamental motor skills has largely been focused on between-skill transfer, but a related fundamental matter for motor skill acquisition is the sequential progression in development within the acquisition of the task-relevant movement pattern of each fundamental motor skill (Newell \& van Emmerik, 1990; Newell \& McDonald, 1994). A key issue is whether the dynamical principles of change in coordination can be mapped to the evolving fundamental core developmental activities and adult culturally promoted motor learning skills.

General Abilities and Individual Differences. The large-scale experimental data sets proposed around the acquisition of fundamental motor skills would be able to take advantage of the opportunity to investigate abilities and individual differences in the learning of new patterns of coordination that emerge through infant and childhood development. This literature is still single handedly guided by the Henry 
(1958) principle of the specificity of learning whereby what is perceived as a single general ability is actually a consequence of many unique abilities. It would be useful to re-examine the abilities and individual differences findings in terms of coordination, control, and skill (Burton \& Rodgerson, 2001).

Instructional Strategies and the Fundamental Motor Skills. The emergence of the infant developmental sequence of fundamental motor skills primarily occurs in the context of home activities rather than being school-based. Furthermore, it has traditionally been held that infant motor skill development does not require instruction in that babies naturally engage and interact with the environment and the fundamental motor skills will emerge. This still puts the onus on parents to provide for a rich environmental context in a way that progressively facilitates infant searching and learning of the fundamental motor skills (Adolph \& Hoch, 2019; Newell, 1986).

There is a need for fresh experimental approaches on instructional strategies for learning the fundamental motor skills and the early stages of their integration and adaptation into other motor skills. The extant research on motor skill acquisition and associated instructional strategies has focused on adults in scaling tasks where the learner can already produce the task-relevant movement coordination pattern. (Newell, 1985). The challenge for the instructor is very different in facilitating the acquisition of a scaling task from one where learning of a new movement pattern is the goal or necessary for achieving a goal (Newell, 1991, 1996).

A constraints approach to instructional strategies holds strong relevance to the acquisition of coordination and the changes evident in learning the core developmental skills and beyond (Davids, Button, \& Bennett, 2008; Newell, 1986). The old and largely untested strategies of whole-part-whole and progressive stages learning (Magill \& Anderson, 2014) also deserve a fresh look under the principles of coordination dynamics that provide a new rationale for the emergence of the qualitative movement coordination patterns and their transitions with practice over developmental time. In the same way that the intra-individual change in motor skill acquisition is linked to the inter-individual change, so too are the within-skills progressions linked to the between-skill progressions (see Figure 2). The role of the fundamental motor skills in the core developmental activities and the subsequent motor learning as an adult would provide a useful examination of the hypothesized generalization of a building block role of the fundamental motor skills.

\section{Fundamental Motor Skills and Assessment Tests}

So far in this paper, the analysis of the literature relating to the concept of 'fundamental' as it applies to motor skills has concentrated on descriptive and experimental studies that speak to the issue. From a practical viewpoint, however, one might also consider the rationale and content of assessment instruments (often called motor ability tests) as they also reflect current thinking on what is fundamental.

There are numerous motor ability tests available in the marketplace (see Table 4 for some examples). They vary in the age range catered to, the objective of the test, its format, and whether the test is norm-referenced or criterion referenced. With regard to objective, some are designed to provide an estimate of where a particular child sits on a normative scale, others focus on the identification of children whose motor development may be atypical, and yet others attempt to do both. 
An important variable in relation to the present discussion is the professional background of the test authors, as this often determines both the theoretical perspective of the authors and the test content. For example, many tests designed to assess children in the 0 - to 2-year-old range are designed by pediatricians or psychologists (Bayley Scales; Denver Developmental Test). These tests are often viewed as a reflection of the development of the nervous system in general terms and used in the follow-up of children born prematurely or who have experienced some sort of birth trauma. Beyond the age of 2 years, the range of professionals widens to include physical therapy (PT), occupational therapy (OT), and physical education (PE) professionals as well as psychologists. Then, one finds tests focusing exclusively on hand function designed by OTs, tests which focus exclusively on gross motor skills designed by PE specialists, and so on. In most cases, these authors use terms such as motor ability, motor competence, and motor function to describe what they are measuring. At this time, the idea that the development of the motor system provides an exclusive window to the nervous system is no longer viable as the effects of culture, experience, and practice are all accepted as affecting performance at any one point in time.

As in all of the fundamental action categories there are, for example, many gait patterns of walking as John Cleese of Monty Python fame showed years ago with his repertoire of silly walks. More formally, van Emmerik, Wagenaar, and van Wegen (1998) and Wagenaar and van Emmerik (2000) have shown that there are several coordination patterns of arm and leg motions that are all perceived as the action of walking. The question arises as to which of the many possible movement patterns should be taken to reflect the action category and be the fundamental motor skill item of locomotion in motor ability tests? Is it the pattern of the first rudimentary steps to emerge or is there an agreed upon exemplar mature gait pattern for walking? Moreover, should walking speed also be considered given this influences stability of gait?

A possible strategy is the implementation of the preferred coordination mode (walking gait) at the preferred speed to walk at a comfortable speed for a reasonable duration. The preferred coordination mode and speed may be seen as generic exemplars of the given motor skill category. The same considerations and

\section{Table 4 The Standardized Better Known and More Frequently Used Motor Ability Tests (in Age Range-Related Order)}

Bayley Scales of Infant and Toddler Development, 3rd Ed (Bayley-III) (infants and toddlers, 1 to 42 months) (motor scale 81 items; Mental scale 163 items) (Bayley, 1969)

Denver Developmental Screening Test, 2nd Ed (DDST-II; birth to 6 yrs) (gross motor 31 items; fine motor 30 items) (Frankenburg \& Dodds, 1967)

Test of Gross Motor Development, Third Edition (TGMD-3; ages 3 to $10.9 \mathrm{yrs}$ ) (version TGMD-3; 13 skills: locomotor 6 skills; ball 7 skills) (Ulrich, 2017)

Movement Assessment Battery for Children, 2nd Ed. (M-ABC-2; 3 to 17 yrs) (Identify impairment; problems with delay in manual dexterity, ball skills, static and dynamic balance) (3 age bands with items varying by band) (Henderson, Sugden, \& Barrett, 2007)

Bruininks-Oseretsky Test of Motor Proficiency, 2nd Ed. (BOT-2; 4-21yrs) in fine and gross motor skills (Bruininks \& Bruininks, 2005) 
decisions need to be made in the setting of a 'prehensile or postural item' in a motor ability test.

If we consider the content of existing tests in the context of the present discussion, it becomes clear that those tests focusing on children age 0 to 2 years reflect well the classification being proposed here. Nearly all of these tests include items that can be grouped under the headings posture, locomotion, and objectinteraction that is what we are labeling fundamental. In most cases, there are many component items under each of the three headings. For example, under the heading posture, head/eye control may be rated, followed by sitting posture, crawling, standing, and so on. In some cases, such items will be "scored" on the basis of achievement only (can do/can't do), and in other cases the method of achievement or movement pattern will become a feature to consider. In fact, recent assessments of the very young infant have also included those examining entirely spontaneous movement as opposed to intentional actions such as raising the head.

When we turn to tests that are designed for children 3 years and upward, the question of whether they adhere to the framework proposed here is a little more difficult. At one level of analysis, one could argue that most do actually include tasks that are designed to assess one or more of the three fundamental motor skill/ action categories. As noted above, there are some tests which only assess object control as it is reflected in hand function (i.e., not including ball skills). There are others which only assess locomotion and object control (as reflected in throwing and catching). The majority cover all three areas and often justify their structure in terms of the factors emerging from statistical analysis as well as theoretical perspective.

However, there are some difficulties with these tests, which are often reflected in the fact that a child's score on one test may not be identical to that on another which purports to test the same behavior. The primary reason for such discrepancy is that authors of tests for children older than 3 years are selecting from a much bigger pool of tasks that they consider to represent the "fundamental" action category in question. So, taking locomotion as an example, beyond the age of 3 years there are myriad activities that could be classed as "locomotion" and test designers pick and choose for different reasons, some simply practical, others relating to psychometric issues of reliability, etc. For example, such tests include hopping, jumping, running, and skipping in numerous different ways. Hopping may be measured on the spot, moving forward, moving sideways, or even in a zig-zag pattern. The problem we then face, of course, takes us back to the question of generalization.

As the relatively simple ability to move forward develops (i.e., walking), how do we conceptualize and measure the many different skills that are built upon it? This is not an easy problem to solve especially within the assessment context. As noted above, there is a dearth of studies that focus on the question, how do children generalize from one basic skill to another? Until we have more data on this important feature of development, we are left with the statistical approach which tells us that task A is more highly correlated with task B than it is with task C. What one then does is select a group of tasks not too highly correlated to represent the fundamental action category one has in mind.

The use of a composite test score in any kind of standardized test has been controversial for decades. Often the score is described as a measure of some overall level of perceptual-motor skill or motor competence. This approach would seem to have some relation to the old but currently out of favor notion of general motor 
ability (Burton \& Rogerson, 2001; Hands, McIntyre, \& Parker, 2018). For others, the use of such an index is rather more pragmatic. When we consider children with difficulties, it is frequently the case that their difficulties extend across all domains of motor behavior. A composite score can be useful when deciding whether the child falls above or below a cut-off point (e.g., 15th percentile). However, in modern times, a clinician would always consider the profile of performance across domains or categories when planning intervention.

\section{Closing Comments}

This paper has provided a framework to rationalize and implement a place in both theory and practice for fundamental motor skills. In this account the fundamental motor skills are the prototypical motor skills of the three major task categories of posture, locomotion, and object-interaction that emerge in infancy. These tasks are typically considered independently on their emergence but blend subsequently satisfying simultaneously two or three of the fundamental category goals (transport, balance equilibrium, object-interaction) in a single motor task. The stability and skill level of infants performing motor tasks continues to be enhanced as adaptations to new task solutions increase the skill repertoire of the child.

The traditional postulations on the building block capabilities of the fundamental motor skills through child development and beyond still warrant systematic evaluation. They carry the most active set of working assumptions by all professional groups that relate to the fundamental motor skills. There is a natural fitting of the coordination dynamics perspective to the problem of decomposing the dynamics of movement patterns and fundamental motor skills in infancy and childhood. There are considerable basic and applied research opportunities on the pathways of the adaptation and generalization of the fundamental motor skills, the core developmental activities, and the many culture-promoted activities. This integration would proceed more rapidly and systematically with enhanced collaborations between the basic and applied groups identified here and with the continued integration of contemporary motor development, motor learning, and motor control. In closing, an old adage seems relevant here in this diverse but exciting research context of fundamental motor skills: namely, "There is nothing as basic as a good applied problem and nothing as applied as a good basic theory."

\section{Notes}

1. The terms motor skills and perceptual-motor skills are used interchangeably. Motor skills have an intention to realize a particular task goal (the outcome) through the coordination and control of the motor system sometimes under additional task constraints (e.g., rules, boundary conditions) as to how the task goal can or will be met. A skill as a noun typically requires a skillful (adjective) performance outcome through considerable practice for meeting the task goal in an effective, predictable, and efficient way that, as needed, is also adaptive to a changing set of conditions. Thus, the term motor skills is broader than the term motor tasks, but inclusive of the task constraints. Motor skills are often taken as synonymous with actions and we follow this tradition here. Again, domain context plays a role in word use. Motor skills is more prevalent in sport and physical activity contexts whereas action is a more common label in academic psychology and the behavioral literature. 
2. The term object-interaction is used to represent the wide range of motor skills that engage or interact with objects. This label is more inclusive to the range of object-related skills than the traditional labels of prehension and object manipulation. The object-interaction can be with any body/limb segment or effector system.

\section{Acknowledgments}

This paper is based on a keynote presentation at the International Motor Development Research Consortium, held in Verona, Italy, September 2019 by I-MDRC, CIAPSE, and IMDR. The author would like to thank Daniela Corbetta, Bob Eckhardt, Sheila Henderson, Inez Rovegno, Michel Wade, the late David Sugden, and an anonymous reviewer for their very helpful comments and critiques on earlier versions of the paper.

\section{References}

Activechiropractice.com. (2016, August 3). Selective functional movement assessment.

Adolph, K.E., Berger, S.E., \& Leo, A.J. (2011). Developmental continuity? Crawling, cruising, and walking. Developmental Science, 14(2), 306-318. PubMed ID: 21399716 doi:10. 1111/j.1467-7687.2010.00981.x

Adolph, K.E., \& Franchak, J.M. (2017). The development of motor behavior. Wiley Interdisciplinary Review of Cognitive Science, 8(1-2), e1430. PubMed ID: 27906517 doi:10.1002/wcs.1430

Adolph, K.E., \& Hoch, J.E. (2019). Motor development: Embodied, embedded, enculturated, enabling. Annual Review of Psychology, 70, 141-164. PubMed ID: 30256718 doi:10.1146/annurev-psych-010418-102836

Barnett, L.M., Stodden, D., Cohen, K.E., Smith, J.J., Lubans, D.R., Lenoir, M., . . Iivonen, S. (2016). Fundamental movement skills: An important focus. Journal of Teaching in Physical Education, 35(3), 219-225. doi:10.1123/jtpe.2014-0209

Bayley, N. (1936). The development of motor abilities during the first three years: A study of sixty-one infants tested repeatedly. Monographs of the Society for Research in Child Development, 1(1), 1-26. doi:10.2307/1165480

Bayley, N. (1969). Manual for the Bayley scales of infant development. New York, NY: Psychological Corp.

Bernstein, N. (1967). The coordination and regulation of movement. Oxford, UK: Pergamon Press.

Bernstein, N.A. (1947). On the construction of movements. In M.L. Latash (Ed.), On the construction of movements. Taylor \& Francis.

Bernstein, N.A. (1996). On dexterity and its development. In M.L. Latash, \& M.T. Turvey (Eds.), Dexterity and its development (pp. 3-244). Mahwah, NJ: Lawrence Erlbaum Associates.

Bertenthal, B., \& von Hofsten, C. (1998). Eye, head, and trunk control: The foundation for manual development. Neuroscience and Biobehavioral Reviews, 22(4), 515-520. PubMed ID: 9595563 doi:10.1016/S0149-7634(97)00038-9

Bramble, D.M., \& Lieberman, D.E. (2004). Endurance running and the evolution of Homo. Nature, 432(7015), 345-352. PubMed ID: 15549097 doi:10.1038/nature03052

Bril, B. (2018). Action, movement, and culture: Does culture shape movement? Kinesiology Review, 7(1), 79-87. doi:10.1123/kr.2017-0060.

Bril, B., \& Sabatier, C. (1986). The cultural context of motor development: Postural manipulation in the daily life of Bambara babies (Mali). International Journal of Behavioral Development, 9(4), 439-453. doi:10.1177/016502548600900403 
Bruininks, R.H, \& Bruininks, V.L. (2005). Bruininks-Oseretsky test of motor proficiency (2nd Ed.). Circle Pines, MN: American Guidance Service.

Bullinger, A. (1990). Posture control during reaching. In H. Bloch, \& B.I. Bertenthal (Eds), Sensory-motor organization and development during infancy and early childhood (pp. 263-271). Dordrecht, Netherlands: Kluwer.

Burton, A.W., \& Rodgerson, R.W. (2001). New perspectives on the assessment of movement skills and motor abilities. Adapted Physical Activity Quarterly, 18(4), 347-365. doi:10.1123/apaq.18.4.347

Carrier, D.R. (1984). The energetic paradox of human running and hominid evolution. Current Anthropology, 25(4), 483-495. doi:10.1086/203165

Chek, P. (2014). The seven primal movements.

Colvin, A.Y., Markos, N.J.E., \& Walker, P.J. (2016). Teaching fundamental motor skills, SHAPE America set the Standard (3rd ed.). Champaign, IL: Human Kinetics,

Daffertshofer, A., Lamoth, C.J.C., Meijer, O.G., \& Beek, P.J. (2004). PCA in studying coordination and variability: A tutorial. Clinical Biomechanics, 19(4), 415-428. PubMed ID: 15109763 doi:10.1016/j.clinbiomech.2004.01.005

Davids, K., Button, C., \& Bennett, S. (2008). Dynamics of skill acquisition. Champaign, IL: Human Kinetics.

Department of Education. (1996). Fundamental movement skills: A manual for classroom teachers. State of Victoria, Australia.

Department of Health and Physical Education. (2011). Fundamental movement skills: A manual for classroom teachers. Ottawa, Canada.

de Vries, J.I., Visser, G.H., \& Prechtl, H.F. (1982). The emergence of fetal behaviour. I. Qualitative aspects. Early Human Development, 7(4), 301-322. PubMed ID: 7169027 doi:10.1016/0378-3782(82)90033-0

Dunsworth, H., Challis, J.H., \& Walker, A.C. (2003). Throwing and bipedalism: A new look at an old idea. In J.L. Kohler, M. Kohler, \& S. Moya-Sola (Eds.), Upright walking (pp. 105-110). Stuttgart, Germany: E. Schweizerbart'sche Verlagsbuchhandlung.

Edelman, G.M., \& Gally, J. (2001). Degeneracy and complexity in biological systems. Proceedings of the National Academy of Sciences of the United States of America, 98(24), 13763-13768. PubMed ID: 11698650 doi:10.1073/pnas.231499798

Fitts, P.M. (1964). Perceptual-motor skills learning. In A.W. Melton (Ed.), Categories of human learning (pp. 243-285). New York, NY: Academic Press.

Fleishman, E.A., Quaintance, M., \& Broedling, L.A. (1984). Taxonomies of human performance: The description of human tasks. New York, NY: Academic Press.

Frankenburg, W.K., \& Dodds, J.B. (1967). The Denver Developmental screening test. Journal of Pediatrics, 71(2), 181-191. PubMed ID: 6029467 doi:10.1016/ S0022-3476(67)80070-2

Gentile, A.M. (1972). A working model of skill acquisition with application to teaching. Quest, 17(1), 3-23. doi:10.1080/00336297.1972.10519717

Gentile, A.M. (1987). Skill acquisition: Action, movement, and the neuromotor processes. In J.H. Carr, R.B. Shepard, A.M. Gentile, \& J.M. Hind (Eds.), Movement science: Foundations for physical therapy in rehabilitation (pp. 93-154). Rockville, MD: Aspen.

Gesell, A. (1929). Maturation and infant behavior pattern. Psychological Review, 36(4), 307-319. doi:10.1037/h0075379

Gesell, A. (1952). Infant development: The embryology of early human behavior. Westport, CT: Greenwood Press.

Grenier, A. (1981). "Liberated" motricity by holding the head during the first weeks of life. Archives Francaises de Pediatrie, 38(8), 557-561. PubMed ID: 7316667

Guthrie, E.R. (1935). The psychology of learning. New York, NY: Harper \& Row. 
Hadders-Algra, M. (2010). Variation and variability: Key words in human motor development. Physical Therapy, 90(12), 1823-1837. PubMed ID: 20966209 doi:10.2522/ ptj.20100006

Hands, B., McIntyre, F., \& Parker, H. (2018). The general motor ability hypothesis: An old idea revisited. Perceptual and Motor Skills, 125(2), 213-233. PubMed ID: 29327979 doi:10.1177/0031512517751750

Haywood, K.M., \& Getchell, N. (2020). Life span motor development (7th ed.). Champaign, IL: Human Kinetics.

Henry, F.M. (1958). Specificity vs generality in learning motor skill. College Physical Education Association, 59, 68-75.

Henderson, S.E., Sugden, D.A., \& Barnett, A.L. (2007). Movement assessment battery for children-2 second edition [Movement ABC-2]. London, UK: The Psychological Corporation.

Hogan, N., \& Sternad, D. (2012). Dynamic primitives of motor behavior. Biological Cybernetics, 106(11-12), 727-739. PubMed ID: 23124919 doi:10.1007/s00422012-0527-1

Horak, F.B., \& Macpherson J.M. (1996). Postural orientation and equilibrium. In Rowell, L.B., \& Sheperd, J.T. (Eds). Handbook of physiology (pp 255-292). Oxford, UK: Oxford University.

Hulteen, R.M., Morgan, P.J., Barnett, L.M., Stodden, D.F., \& Lubans, D.R. (2018). Development of foundational movement skills: A conceptual model for physical activity across the lifespan. Sports Medicine, 48(7), 1533-1540. PubMed ID: 29524160 doi:10.1007/s40279-018-0892-6

Iverson, J.M. (2010). Developing language in a developing body: the relationship between motor development and language development. Journal of Child Language, 37(2), 229-261. PubMed ID: 20096145 doi:10.1017/S0305000909990432

Kelso, J.A.S. (1985, December 2018). Dynamic patterns: The self-organization of brain and behavior. Cambridge, MA: The MIT Press.

Knapp, B. (1963). Skill and sport. London, UK: Routledge and Kegan Paul.

Kugler, P.N., Kelso, J.A.S., \& Turvey, M.T. (1982). On the control and coordination of naturally developing systems. In J.A.S. Kelso\& J.E. Clark (Eds.), The development of movement control and co-ordination (pp. 5-78). New York, NY: Wiley.

Largo, R.H., \& Kakebeeke, T.H. (1994). Fine manipulative abilities in the first years of life. In E. Fedrizzi, G. Avanzini, \& P. Crenna (Eds.), Motor development in children (pp. 33-40). London, UK: John Libbey.

Logan, S.W., Ross, S.M., Chee, K., Stodden, D.F., \& Robinson, L.E. (2018). Fundamental motor skills: A systematic review of terminology. Journal of Sports Sciences, 36(7), 781-796. PubMed ID: 28636423 doi:10.1080/02640414.2017.1340660

Lubans, D.R., Morgan, P.J., Cliff, D.P., Barnett, L.M., \& Okely, A.D. (2010). Fundamental movement skills in children and adolescents. Sports Medicine, 40(12), 1019-1035. PubMed ID: 21058749 doi:10.2165/11536850-000000000-00000

Luzzini-Seigel, J., Hogan, T.P., Rong, P., \& Green, J.R. (2015). Longitudinal development of speech motor control; motor and linguistic factors. Journal of Motor Learning and Development, 3(1), 53-68. PubMed ID: 27047981 doi:10.1123/jmld. 2014-0054

Magill, R., \& Anderson, D. (2014). Motor learning and control: Concepts and applications. Singapore: McGraw-Hill.

Majnemer, A., \& Barr, R.G. (2005). Influence of supine sleep positioning on early motor development acquisition. Developmental Medicine and Child Neurology, 47(6), 370376. PubMed ID: 15934485 doi:10.1017/S0012162205000733

Marzke, M.W. (2013). Toolmaking, hand morphology, and fossil hominins. The philosophical transactions of the royal society, 368(1630), 20120414. PubMed ID: 24101624 doi:10.1098/rstb.2012.0414 
McGinnis, P.M., \& Newell, K.M. (1982). Topological dynamics: A framework for describing movement and its constraints. Human Movement Science, 1(4), 289305. doi:10.1016/0167-9457(82)90017-3

McGraw, M.B. (1943). The neuromuscular maturation of the human infant. New York, NY: Columbia University Press.

McManus, M. (2010). Fundamental motor skills. Coaching the coaches. Retrieved from https://www.google.com/search?client=firefox-b-1-d\&q=McManus+fundamental++ motor+skills\&channel $=$ cus 2

Mitra, S., Amazeen, P.G., \& Turvey, M.T. (1998). Motor learning as decreasing active (dynamical) degrees of freedom. Human Movement Science, 17(1), 17-65. doi:10. 1016/S0167-9457(97)00023-7

Muchisky, M., Gershkoff-Stowe, L., Cole, E., \& Thelen, E. (1996). The epigenetic landscape revisited: A dynamic interpretation. In C. Rovee-Collier (Ed.), Advances in infancy research (Vol. 10, pp 121-159). Norwood. NJ: Ablex.

Newell, K.M. (1978). Some issues on action plans. In G.E. Stelmach (Ed.), Information processing in motor control and learning. New York, NY: Academic Press.

Newell, K.M. (1985). Coordination, control and skill. In D. Goodman, I. Franks, \& R. Wilberg (Eds.), Differing perspectives in motor learning, memory and control (pp. 295-317). Amsterdam, Netherlands: North-Holland.

Newell, K.M. (1986). Constraints on the development of coordination. In M.G. Wade\& H.T.A. Whiting (Eds.), Motor skill acquisition in children: Aspects of coordination and control (pp. 341-360). Amsterdam, Netherlands: Martinies NIJHOS.

Newell, K.M. (1991). Motor skill acquisition. Annual Review of Psychology, 42(1), $213-$ 237. PubMed ID: 2018394 doi:10.1146/annurev.ps.42.020191.001241

Newell, K.M. (1996). Change in movement and skill: Learning, retention, and transfer. In M. Latash\& M. Turvey (Eds.), Dexterity and its development (pp. 393-429). Hillsdale, NJ: Erlbaum.

Newell, K.M., \& Jordan, K.J. (2007). Task constraints and movement organization: A common language. In W.E. Davis (Ed.), An ecological approach to human movement: Linking theory, research and practice. Champaign, IL: Human Kinetics.

Newell, K.M., \& Liu, Y.-T. (2014). Dynamics of motor learning and development across the lifespan. In P.C.M. Molenaar, R. Lerner, \& K.M. Newell (Eds.), Handbook of developmental systems theory and methodology (pp. 316-342). New York, NY: Guilford Publications.

Newell, K.M., Liu, Y.-T., \& Mayer-Kress, G. (2003). A dynamical systems interpretation of epigenetic landscapes for infant motor development. Infant Behavior and Development, 26(4), 449-472. doi:10.1016/j.infbeh.2003.08.003

Newell, K.M., Liu, Y.-T., \& Mayer-Kress, G. (2009). Time scales in connectionist and dynamical systems approaches to learning and development. In J.P. Spencer, M.S.C. Thomas, \& J.L. McClelland (Eds.), Toward a unified theory of development? Connectionism and dynamic systems theory re-considered (pp. 119-138). New York, NY: Oxford University Press.

Newell, K.M., \& McDonald, P.V. (1994). Learning to coordinate redundant biomechanical degrees of freedom. In S. Swinnen, H. Heuer, J. Massion, \& P. Casaer (Eds.), The control and modulation of patterns of inter-limb coordination: A multidisciplinary perspective (pp.515-536). New York, NY: Academic Press.

Newell, K.M., \& Morrison, S. (2016). The evolving dynamical landscape of movement forms: A degrees of freedom perspective. Kinesiology Review, 5(1), 4-14. doi:10.1123/ kr.2015-0047

Newell, K.M., \& van Emmerik, R.E.A. (1990). Are Gesell's developmental principles general principles for the acquisition of coordination. In J.E. Clark\& J.H. Humphrey (Eds.), Advances in motor development research (Vol. 3, pp. 143-164). New York, NY: AMS Press. 
Newell, K.M., \& Wade, M.G. (2018). Physical growth, body scale and perceptual-motor development. In J. Plumert (Ed.), Advances in child development and behavior (Vol. 55, pp 205-242). Amsterdam, Netherlands: Elsevier.

Oriel, K.N., Frazier, K., Lebron, M., Pinkerton, C., \& Townsley, T. (2006). The impact of the back to sleep campaign on gross motor development. Pediatric Physical Therapy, 18(1), 102. doi:10.1097/00001577-200601810-00060

Poulton, E.C. (1957). On prediction in skilled movements. Psychological Bulletin, 54(6), 467-478. PubMed ID: 13485273 doi:10.1037/h0045515

Prechtl, H.F.R. (1986). Prenatal motor development. In M.G. Wade\& H.T.A. Whiting (Eds.), Motor development in children: Aspects of coordination and control (pp. 5364). Dordrecht, Netherlands: Martinus Nijhoff.

Roberton, M.A. (1977). Stability of stage categorizations across trials: Implications for the "stage theory" of over arm throw development. Journal of Human Movement Studies, 3, 49-59.

Roberton, M.A., \& Halverson, L.E. (1984). Developing children: Their changing movement. Philadelphia, PA: Lea \& Febiger.

Rochat, P. (1992). Self-sitting and reaching in 5- to 8-month-old infants: The impact of posture and its development on early eye-hand coordination. Journal of Motor Behavior, 24(2), 210-220. PubMed ID: 14977620 doi:10.1080/00222895.1992.9941616

Sands, R.R., \& Sands, L.R. (Eds.). (2010). The anthropology of sport and human movement. Boulder, CO: Lexington Books.

Schmidt, R.A., \& Lee, T.D. (2012). Motor control and learning: A behavioral emphasis (5th ed.). Champaign, IL: Human Kinetics.

Seefeldt, V. (1980). Developmental motor patterns: Implications for elementary school physical fitness. In C.H. Nadeau, Halliwell W.R., Newell, K.M., \& Roberts, G.C. (Eds.), Psychology of motor behavior and sport (pp. 314-323). Champaign, IL: Human Kinetics.

Shirley, M.M. (1931). The first two years: A study of twenty-five babies. Vol 1. Postural and locomotor development. Minneapolis, MN: University of Minnesota Press.

Shumway-Cook, A., \& Woollacott, M.H. (2016). Motor control: Translating research into clinical practice (5th ed.), South Holland, Netherlands: Wolters Kluwer.

Singer, R.N., \& Gerson, R.F. (1981). Task classification and strategy utilization in motor skills. Research Quarterly for Exercise and Sport, 52(1), 100-116. PubMed ID: 7232856 doi:10.1080/02701367.1981.10609301

Sport New Zealand. (2012). Fundamental movement skills among children in New Zealand. Wellington, New Zealand: Author.

Stanford, C. (2003). Upright: The evolutionary key to becoming human. Boston, MA: Houghton Mifflin.

Sugden, D., \& Wade, M. (2013). Typical and atypical motor development. London, UK: Mac Keith Press.

Super, C.M. (1976). Environmental effects on motor development: The case of "African Infant Precocity". Developmental Medicine and Child Neurology, 18(5), 561-567. PubMed ID: 976610 doi:10.1111/j.1469-8749.1976.tb04202.x

Thelen, E., \& Smith, L.B. (1994). A dynamic systems approach to the development of cognition and action. Cambridge, MA: MIT Press.

Touwen, B.C.L. (1976). Neurological development in infancy. Clinics of developmental medicine, no. 58. London, UK: Heinemann Medical Books.

Turvey, M.T. (1990). Coordination. American Psychologist, 45(8), 938-953. PubMed ID: 2221565 doi:10.1037/0003-066X.45.8.938

Ulrich, D.A. (2017). Introduction to the special section: Evaluation of the psychometric properties of the TGMD-3. Journal of Motor Learning and Development, 5(1), 1-4. doi:10.1123/jmld.2017-0020 
Van der Geert, P., Savelsbergh, G., \& Van der Maas, H. (Eds.). (1999). Non-linear developmental processes. Koninklijke, Netherlands: Royal Netherlands Arts and Sciences.

Van Emmerik, R.E.A., Wagenaar, R.C., \& Wegen, E. (1998). Inter-limb coupling patterns in human locomotion: Are we bipeds or quadrapeds? Annals of New York Academy of Sciences, 860, 539-542.

Waddington, C.H. (1957). The strategy of the genes. London, UK: George Unwin \& Unwin.

Wagenaar, R.C., \& van Emmerik, R.E.A. (2000). Resonant frequencies of arms and legs identify different walking patterns. Journal of Biomechanics, 33(7), 853-861. PubMed ID: 10831760 doi:10.1016/S0021-9290(00)00020-8

Warren, W.H. (2006). The dynamics of perception and action. Psychological Review, 113(2), 358-389. PubMed ID: 16637765 doi:10.1037/0033-295X.113.2.358.

WHO Multicentre Growth Reference Study Group. (2006). Motor development study: Windows of achievement for six gross motor developmental milestones. Acta Paediatrica, 85(Suppl. 450), 86-95. PubMed ID: 16817682

Wickstrom, R.L. (1977). Fundamental movement patterns. Philadelphia, PA: Lea \& Febiger.

Wild, M. (1938). The behavior pattern of throwing and some observations concerning the course of development in children. Research Quarterly, 9(1), 20-24. doi:10.1080/ 23267429.1938.11802445 